\title{
Application of Monte Carlo Simulation to Generating System Well-Being Analysis Considering Renewable Sources
}

\author{
Armando M. Leite da Silva, Luiz Antônio F. Manso, Warlley S. Sales, Leonidas C. Resende, \\ Manuel J.Q. Aguiar, Manuel A. Matos, João A. Peças Lopes, Vladimiro Miranda
}

\begin{abstract}
This paper presents an application of Monte Carlo chronological simulation to evaluate the reserve requirements of generating systems, considering renewable energy sources. The idea is to investigate the behavior of reliability indices, including those from the well-being analysis, when the major portion of the energy sources is renewable. Renewable in this work comprises bydroelectric, mini-hydroelectric and wind power sources. Case studies on a configuration of the Portuguese Generating System are presented and discussed.
\end{abstract}

Index Terms--Power system reliability, Generating system adequacy, Monte Carlo simulation, Renewable energy sources.

\section{INTRODUCTION}

$\mathrm{R}$ ENEWABLE energy technologies will take a greater share of the electricity generation mix in order to minimize the dependence on oil and the emission of $\mathrm{CO}_{2}$. While contributions from renewable energy sources for electricity production is small, with the exception of hydro, their market penetration is growing at a much faster rate than any other conventional source. Although there are still many potential hydro sites in the world, severe restriction based mainly on environmental aspects have limited their exploitation [1].

Wind is undoubtedly the most popular source of green electricity around the world. At the end of 2000 , the world wind energy capacity was $7.5 \mathrm{GW}$, of which $70 \%$ in Europe. The European Wind Energy Association has a target of 60 GW of installed capacity by 2010 . According to Directive 2001/77/EC [2], new capacities for producing electricity from renewable sources in Portugal, for instance, will increase at a rate twice as high as the rate of increase of gross national electricity consumption. Considering a peak load of $10.6 \mathrm{GW}$ forecasted for the year 2010 in Portugal, it means that 9.1GW must come from renewable sources, from which $3.8 \mathrm{GW}$ will come from wind sources and the rest from hydro, mini-hydro power stations and other power sources.

This work was supported in part by the DGGE (Direcção Geral de Geologia e Energia), Portugal.

A.M. Leite da Silva (armando@power.inescporto.pt), L.C. Resende, M.J.Q. Aguiar, M.A. Matos, J.A. Pecas Lopes and V. Miranda are with the Power System Unit, INESC Porto, Portugal. Prof. Leite da Silva is on sabbatical leave from the Institute of Electrical Eng., Federal University, Itajubá, UNIFEI, Brazil.

L.A.F. Manso and W.S. Sales are with Electrical Eng. Dept., Federal University of Såo Joăo del Rei, UFSJ, Brazil.
The previous values put system planners under a huge pressure to come out with solutions bearing in mind the new technologies available. Moreover, the number of random variables and system complexities increase tremendously when renewable energy sources are added to the system due to the fluctuating capacity levels of these sources.

Deterministic based approaches generally have very attractive characteristics such as simple implementation, straightforward understanding, and easy assessment and judgment by planners in relation to severe conditions like network outages and system peak load. Unfortunately, the perception of many planning engineers that past experience in addition to some known critical situations is enough to assess system risk conditions is not valid. In addition, past experience with renewable sources like wind power is very limited. However, the principles of some deterministic standards (e.g. "N-1" criterion) must be recognized as attractive.

Methodologies based on probability concepts can be extremely useful in assessing the performance of power systems [3]. They have been successfully applied to many areas including generation capacity planning, operating reserve assessment, distribution systems etc. The proper measure of risk can only be achieved by recognizing the probabilistic nature of the relevant power system parameters.

A new framework, named system well-being analysis [4-7], has been developed combining the deterministic perception with probability concepts. This new framework reduces the gap between deterministic and probabilistic approaches by providing the ability to measure the degree of success of any operating system state. In a well-being analysis, success states are further split into healthy and marginal states, using the previously mentioned engineers' perception as the criterion. Fig. 1 illustrates the new system states according to the wellbeing framework.

Well-being analysis has been applied in the last decade to areas such as generating systems, operating reserve assessment and composite generation and transmission systems. Chronological or sequential Monte Carlo simulation has been used for generating system well-being analysis, considering the loss of the largest available unit in the system as the deterministic criterion. These concepts can be extremely useful for dimensioning the static generating capacity (i.e. adequacy) considering renewable resources [8]-[20]. 


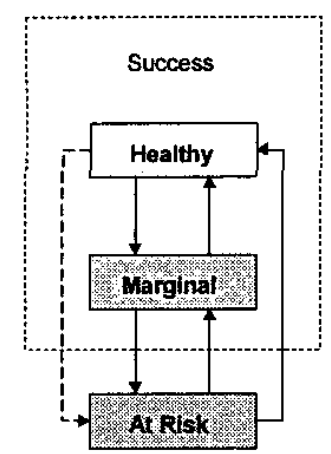

Fig. 1. Model for system well-being analysis.

This paper presents an application of chronological Monte Carlo simulation to evaluate the reserve requirements of generating systems, considering renewable energy sources. The idea is to investigate the behavior of reliability indices, including those from the well-being analysis, when the major portion of the energy sources is renewable. Renewable comprises wind [8]-[18], hydroelectric [19] and minihydroelectric power sources. Case studies on configurations of the Portuguese Generating System are presented through several indices, including the loss of load cost [20], and discussed.

\section{PROPOSED METHODOLOGY}

The estimates of reliability indices are based on two distinct representations: state space and chronological modeling. State enumeration (analytical) and non-sequential Monte-Carlo simulation (MCS) methods are examples of state space based algorithms, where Markov models are usually used for both equipment and load state transitions. Therefore, states are selected and evaluated without considering any chronological connection. Conversely, sequential simulation can perceive all chronological aspects and, hence, it is able to correctly represent equipment aging process, time varying loads, spatial and time correlation aspects etc. Chronological modeling, however, implies that two consecutive state samples differ from each other on only one state component and, therefore, it requires considerably more computational effort. A method named pseudo-chronological MCS has been recently proposed [21], which preserves the efficiency of the non-sequential MCS and the ability to model chronological load curves in sequential simulation. It uses a special Markov load model, which accurately captures the impact of time varying loads.

Chronological or sequential MCS is very convenient due to its flexibility, as it allows the representation of nonexponential residence times, useful when dealing with chronological processes. Moreover, as dealing with renewable energy sources and their natural uncertainties, due to hydrologic inflow sequences, wind speed variations etc., chronological MCS seems to be the most effective way to adequately model and solve these difficulties.

\section{A. Chronological Monte Carlo Simulation}

The operation history of system states, for a simulation period $\mathrm{T}$, is based on stochastic models of the components and on the load model. The initial operating state is sampled from the probability distributions of the generating equipment. After evaluating each state, performance indices are estimated using test-functions $\mathrm{G}(\mathrm{t})$

$$
E(G)=\frac{l}{T} \int_{0}^{T} G(t) d t .
$$

Each performance index can be estimated using a suitable test-function. The failure probability, for instance, corresponds to the expected value of an indicator function where $G(t)=1$ if the system associated with time $t$ is a failure state; otherwise $G(t)=0$. Another way of estimating the expected value of $G(t)$ is shown as follows

$$
\tilde{E}(G)=\frac{1}{N Y} \sum_{k=1}^{N Y} G\left(y_{k}\right)
$$

where NY is the no. of simulated years and $y_{k}$ is a sequence of system states in year $\mathrm{k}$. For instance, the energy not supplied will be the summation of unsupplied energy associated with each interruption of a simulated year. The uncertainty around the estimated indices is given by the variance of the estimator:

$$
V(\widetilde{E}(G))=\frac{V(G)}{N Y}
$$

where $V(G)$ is the variance of the test-function. The convergence of the simulation process is tested using the coefficient of variation $\beta$ [21].

$$
\beta=\sqrt{V(\widetilde{E}[G])} / \widetilde{E}[G]
$$

\section{1) Modeling of Hydro and Thermal Units}

A two-state Markov model is used for all hydro and thermal generating units. They are specified through their failure and repair rates. Clearly, any non-Markovian model could be used if the necessary parameters are available. The capacities of the hydro units will be defined for each month, according to the corresponding hydrological series. These series are defined for each hydraulic basin based on historical data and aim to capture the historical inflows, reservoir volumes and type of operation. Conversely, the thermal unit capacities are fixed and pre-specified.

2) Modeling of Wind Units

Usually, in a wind power site, there are several generating units and they will be grouped into an equivalent multi-state Markov model. Only two parameters are necessary: failure and repair rates. The productions of the wind generating units will be defined for each hour, according to the wind series of the geographic region. The wind series try to capture the wind speed and power conversion characteristics. 


\section{3) Modeling of Mini-Hydro}

Mini-hydro units are modeled similarly to the hydro generating units, but in this case, they are grouped into multistate-units to simplify the modeling processing. Due to the lack of specific data in relation to the hydrological basin where they are located, only one average series per year is used to model the capacity variations with time.

\section{4) Modeling of Co-Generation}

Co-generating units are modeled similarly to the thermal units, but like in the previous case, they are clustered as well. Moreover a utilization factor is specified, which models the actual co-generation power used by the system. This factor varies during the year following the tariff attractiveness and/or the industry production cycle.

\section{5) Maintenance Aspects}

A certain amount of power generation will be specified per month in order to capture the maintenance activities along the year. In order to deal with that, the proposed chronological MCS algorithm, according to the generating power on maintenance, adequately increases the hourly load curve.

6) Load Characteristics

A chronological load model containing 8760 levels, corresponding to each hour, is used. The chronological MCS will sequentially follow these load steps during the simulation process. A coefficient of variation (say 1 or $2 \%$ ) can be specified to simulate forecasted peak load uncertainties.

\section{B. Conventional Reliability Indices}

The conventional reliability indices are: LOLP $=$ loss of load probability; LOLE = loss of load expectation; EPNS = expected power not supplied; EENS = expected energy not supplied; LOLF $=$ loss of load frequency; LOLD $=$ loss of load duration; LOLC $=$ loss of load cost.

\section{Well-being Indices}

The well-being indices are: $E_{H}=$ expected healthy hours, which is the expected number of hours in a period (e.g. year) the system will stay in healthy states; $\mathrm{E}_{\mathrm{M}}=$ expected marginal hours, which is the expected number of hours in a period (e.g. year) the system will stay in marginal states; $F_{H}$ and $F_{M}=$ expected frequency associated with healthy and marginal states, respectively; $D_{H}$ and $D_{M}=$ expected duration of system residing in healthy and marginal states, respectively. The deterministic criterion is the loss of the largest available unit in the system.

\section{Computational Program Characteristics}

The implementation of the previous models is carried out through a Fortran (calculations mode) and Visual Basic (user interactive mode) algorithm. The convergence process is tracked through a coefficient of variation specified for the EENS index. Usually, once ensuring the convergence of EENS index, the others will have converged as well. The probability distributions of all, conventional and well-being, reliability indices are also evaluated.

\section{APPLICATION RESULTS}

The proposed algorithm has been tested under several conditions with different systems. Two cases using the Portuguese Generating System (PGS) will be discussed as follows. The first case will show the results using the PGS configuration for the year 2002. The idea is to evaluate this configuration to establish certain reliability parameters or standards. The second case will illustrate the results obtained with the proposed algorithm considering a potential configuration for the year 2010. This is part of the expansion plan studies of the PGS.

\section{A. Portuguese Generating System - Basic Characteristics}

Considering the configuration for the year 2002, the PGS has 479 units with a total installed capacity of $10.90 \mathrm{GW}$, distributed as follows: $4.15 \mathrm{GW}$ (Hydro); $4.86 \mathrm{GW}$ (Thermal); $0.17 \mathrm{GW}$ (Wind); $0.30 \mathrm{GW}$ (Mini-hydro); and $1.42 \mathrm{GW}$ (Cogeneration). The annual peak load occurred in December and it was approximately $7.40 \mathrm{GW}$. Bearing in mind these two values, the static system reserve corresponds to $32 \%$ of the installed capacity. Also, the amount of renewable power in the system is $42 \%$ of the total capacity. In 2010 , this amount will correspond to $51 \%$ of the total capacity, from this total 3.75 GW of wind power.

In order to calculate the LOLC index, a unit interruption cost of $1.5 \mathrm{E} / \mathrm{kWh}$ is used for all customer classes. The major classes are: Industrial (42\%); Services/Commercial (30\%); Residential (25\%); Agricultural/Rural (2\%) and Transportation (1\%). The next items provide more details on the PGS.

1) Hydro Power Generation

In 2002, there were 35 hydro power plants with a total of 90 generating units. In this study, 7 hydrological basins in Portugal are considered (Lima, Cávado, Douro, Mondego, Tejo, Ave and Guadiana), and 10 years of monthly hydrological conditions are used $(1993-2002)$. Figure 2 shows the capacity variations for a typical basin, and similar pattern fluctuations were obtained with other basins. Typical values for the two-state Markov model are: failure rate $(\lambda=4.62$ occ./year) and mean time to repair (MTTR $=25$ hours).

\section{2) Thermal Power Generation}

In 2002, there were 11 thermal power plants (not including co-generation) with 32 units. These include coal, gas and oil power generation. Most power stations are close to the major load centers: Lisbon (1.84 GW) and Oporto (1.04 GW). Typical values for the two state model ranges from 6.8 to 23 occ./year for the failure and 30 to 50 hours for the MTTR.

\section{3) Wind Power Generation}

About 100 wind-generating turbines (units) were in the PGS in 2002 , corresponding to $1.5 \%$ of the total system capacity. Bearing in mind the wind series, Portugal was divided into 3 wind regions: North, Center and South. In future, these regions will be further divided into coastal and interior. Figure 3 shows these boundaries and the major electric network system. Figure 4 shows the average hourly wind power series for the spring period, which are obtained, after statistical processing, from actual wind speed measurements. 


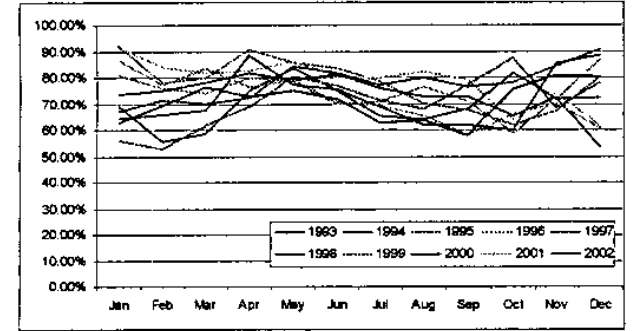

Fig, 2. Hydrological Series (Monthly) - Typical Basin.

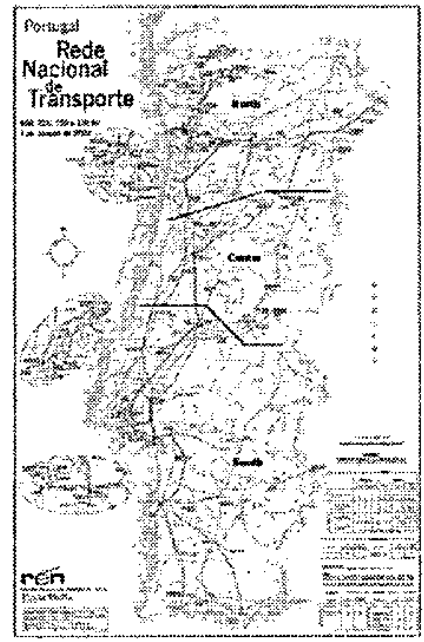

Fig. 3. Wind Regions and the Portuguese Network.

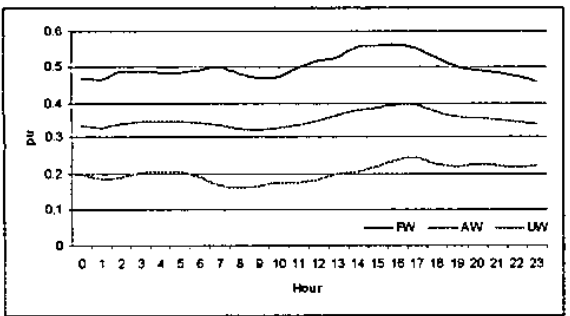

Fig. 4. Wind Power Series for Spring (Center Region): UW - Unfavorable Winds; AW - Average Winds; FW - Favorable Winds.

\section{4) Mini-Hydro Generation}

As previously stated, only one average series per year is used to model the mini-hydro capacity variations with time. Figure 5 illustrates two curves corresponding to years 1996 (favorable conditions) and 2001 (unfavorable conditions).

5) Co-Generation, Maintenance and Load

Figure 6 shows the degree of utilization of co-generation in the PGS in 2002. Figure 7 illustrates the amount of power generation scheduled for maintenance in 2002. Figure 8 shows a typical daily load curve for the 2002 winter season. The complete curve used by the algorithm has 8760 load levels. Similar patterns are used for the proposed chronological MCS.

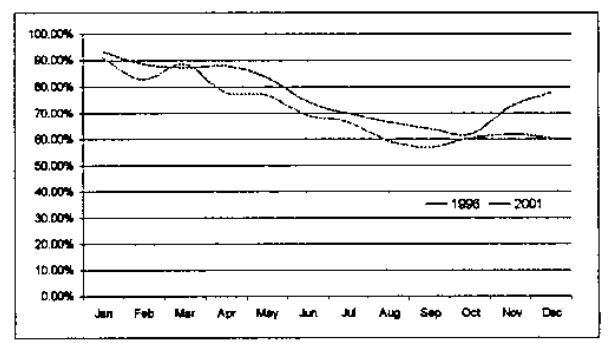

Fig. 5. Hydrological Series (Monthly) for Mini-Hydro Units: 1996 and 2001

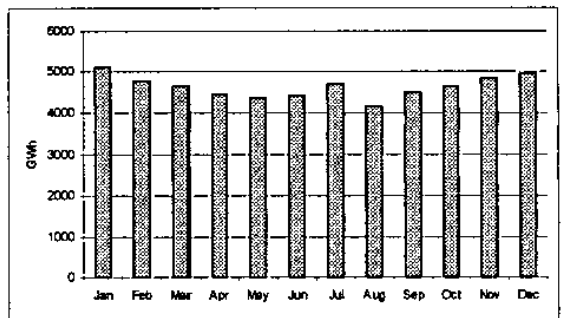

Fig. 6. Co-Generation Utilization (Monthly): 2002.

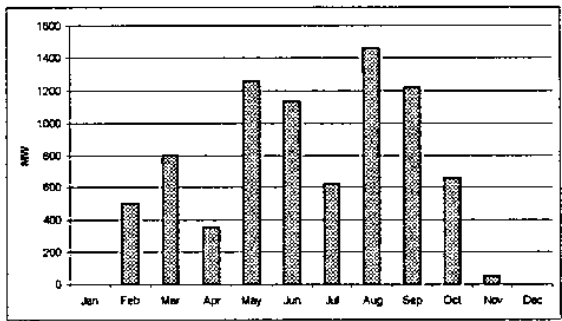

Fig. 7. Power Generation on Maintenance (Monthly): 2002.

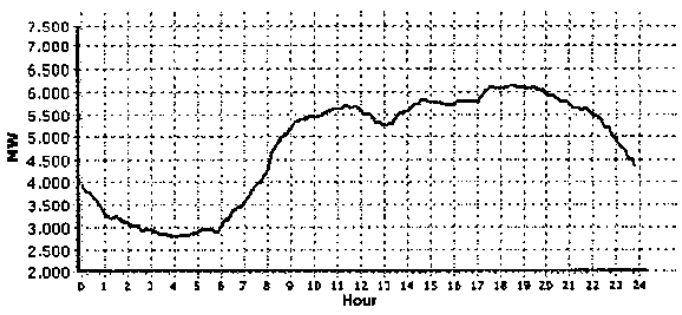

Fig. 8. Typical Load Curve (December, 2002).

\section{B. Results}

The proposed chronological MCS algorithm is being tested with several configurations of the PGS. The idea is to determine the required amount of system generating capacity to ensure an adequate power supply, bearing in mind not only the uncertainties from the equipment availabilities but also the uncertainties due to the renewable power sources capacity variations. This study is being carried out considering a horizon of 10 years (2004-2013). Different scenarios involving not only hydro and wind unfavorable conditions but also co-generation usage and maintenance strategies are analyzed. 


\section{1) Analysis for the 2002 Configuration}

In order to define reliability standards for the PGS, the 2002 Configuration is used. Although several operating conditions or cases have been tested, only four of them will be discussed. For the Base case, all historical hydrological and wind series are simulated with the 2002 Configuration. For the HW case, the most severe hydrological year and the most severe wind condition are simultaneously used. The HWM case is similar to the previous one but the amount of power on maintenance is increased by $20 \%$. The $\mathrm{HW}_{\mathrm{Z}}$ case is similar to " $\mathrm{HW}$ " but instead of using the most severe observed wind series, this condition is made nil, i.e. no wind is available during an entire year. Undoubtedly, this is an extremely severe wind condition.

Tables I and II show the conventional and well-being indices, respectively, for the 2002 Configuration. The numbers between brackets are the corresponding coefficient of variation $\beta$. As it can be seen from both tables, this PGS configuration is very robust. The worst condition occurs for "HWM", resulting indices like: LOLE $=2.585$ hours/year and the LOLC $=556900 € /$ year. Under this condition, the system will spend, on average, 18.47 hours in marginal states and once it gets there, it stays, on average, 1.503 hours. The frequency of marginal states is $\mathbf{1 2 . 2 9}$ occurrences per year. If a LOLE index equal to 10 hours per year was set as the acceptable limit for the PGS, the 2002 Configuration would be approved.

Figure 8 shows the cumulative and individual probability functions associated with the four conditions: Base, HW, $\mathrm{HWM}$ and $\mathrm{HW}_{\mathrm{Z}}$. As it can be seen, the chances of overcoming the previous LOLE limit are about $7 \%$, considering the worst case (i.e. "HWM").

TABLE I

CONVENTIONAL RELIABILITY INDICES - 2002

\begin{tabular}{|c|c|c|c|c|c|}
\hline $\begin{array}{l}\text { Case } \\
\text { Cas }\end{array}$ & $\begin{array}{l}\text { COL E } \\
(\mathrm{b} / \mathrm{y})\end{array}$ & $\begin{array}{l}\text { EWNS } \\
(\text { MWh/y) }\end{array}$ & $\begin{array}{l}\text { LOLF } \\
(\text { occ } y)\end{array}$ & $\begin{array}{r}\mathbf{L O L D} \\
\text { (b) }\end{array}$ & $\begin{array}{l}\text { LOLC } \\
\times 10^{6} \in y^{6}\end{array}$ \\
\hline Base & $\begin{array}{l}0.1868 \\
(3.38 \%)\end{array}$ & $\begin{array}{c}22.72 \\
(5.00 \%)\end{array}$ & $\begin{array}{l}0.1303 \\
(2.76 \%)\end{array}$ & $\begin{array}{c}1.434 \\
(3.73 \%)\end{array}$ & $\begin{array}{l}0.0341 \\
(5.00 \%)\end{array}$ \\
\hline HW & $\begin{array}{l}0.6052 \\
(3.22 \%)\end{array}$ & $\begin{array}{c}81.15 \\
(5.00 \%)\end{array}$ & $\begin{array}{l}0.3814 \\
(2.67 \%)\end{array}$ & $\begin{array}{c}1.587 \\
(3.65 \%) \\
\end{array}$ & $\begin{array}{l}0.1217 \\
(5.00 \%)\end{array}$ \\
\hline HWM & $\begin{array}{c}2.585 \\
(3.39 \%)\end{array}$ & $\begin{array}{c}371.2 \\
(5.00 \%)\end{array}$ & $\begin{array}{c}1.523 \\
(2.78 \%)\end{array}$ & $\begin{array}{c}1.698 \\
(3.99 \%) \\
\end{array}$ & $\begin{array}{l}0.5569 \\
(5.00 \%)\end{array}$ \\
\hline $\mathrm{HW}_{2}$ & $\begin{array}{l}0.7245 \\
(3.28 \%)\end{array}$ & $\begin{array}{c}96.89 \\
(5.00 \%)\end{array}$ & $\begin{array}{l}0.4602 \\
(2.74 \%)\end{array}$ & $\begin{array}{c}1.574 \\
(3.73 \%)\end{array}$ & $\begin{array}{l}0.1453 \\
(5.00 \%)\end{array}$ \\
\hline
\end{tabular}

TABLE II

WELL-BEING INDICES - 2002

\begin{tabular}{|c|c|c|c|c|c|c|}
\hline $\begin{array}{c}\text { Case } \\
\text { (n) } \\
\text {. }\end{array}$ & $\begin{array}{l}\mathrm{E}_{\text {W }} \\
(\mathrm{W} / \mathrm{y})\end{array}$ & $\begin{array}{l}\mathbf{E}_{\mathrm{M}} \\
(\mathrm{h} / \mathrm{y})\end{array}$ & $\begin{array}{l}\mathrm{F}_{\mathrm{H}} \\
(\mathrm{occ} / \mathrm{y})\end{array}$ & $\begin{array}{l}F_{N} \\
(0 \mathrm{cc} / y)\end{array}$ & $\begin{array}{l}\mathbf{D}_{\mathbf{H}} \\
\mathbf{n}^{2} \\
(\mathbf{h})\end{array}$ & $\begin{array}{c}\text { D }_{M} \\
\text { (h) }\end{array}$ \\
\hline Base & $\begin{array}{c}8758 \\
(0.01 \%) \\
\end{array}$ & $\begin{array}{c}1.911 \\
(5.00 \%)\end{array}$ & $\begin{array}{c}1.290 \\
(4.41 \%)\end{array}$ & $\begin{array}{r}1.414 \\
(4.56 \%) \\
\end{array}$ & $\begin{array}{c}6787 \\
(4.41 \%) \\
\end{array}$ & $\begin{array}{c}1.352 \\
(6.07 \%) \\
\end{array}$ \\
\hline HW & $\begin{array}{r}8754 \\
(0.01 \%) \\
\end{array}$ & $\begin{array}{c}5.307 \\
(4.99 \%) \\
\end{array}$ & $\begin{array}{r}3.381 \\
(4.43 \%) \\
\end{array}$ & $\begin{array}{c}3.788 \\
(4.71 \%) \\
\end{array}$ & $\begin{array}{r}2589 \\
(4.43 \%) \\
\end{array}$ & $\begin{array}{r}1.401 \\
(6.30 \%) \\
\end{array}$ \\
\hline HWM & $\begin{array}{r}8739 \\
(0.02 \%) \\
\end{array}$ & $\begin{array}{c}18.47 \\
(4.98 \%) \\
\end{array}$ & $\begin{array}{r}10.69 \\
(4.37 \%) \\
\end{array}$ & $\begin{array}{c}12.29 \\
(4.94 \%) \\
\end{array}$ & $\begin{array}{r}817.2 \\
(4.37 \%) \\
\end{array}$ & $\begin{array}{r}1.503 \\
(6.49 \%) \\
\end{array}$ \\
\hline $\mathrm{HW}_{\mathrm{Z}}$ & $\begin{array}{c}8753 \\
(0.01 \%)\end{array}$ & $\begin{array}{c}6.446 \\
(5.00 \%) \\
\end{array}$ & $\begin{array}{c}3.988 \\
(4.35 \%)\end{array}$ & $\begin{array}{c}4.481 \\
(4.62 \%)\end{array}$ & $\begin{array}{c}2195 \\
(4.34 \%)\end{array}$ & $\begin{array}{c}1.438 \\
(6.25 \%)\end{array}$ \\
\hline
\end{tabular}

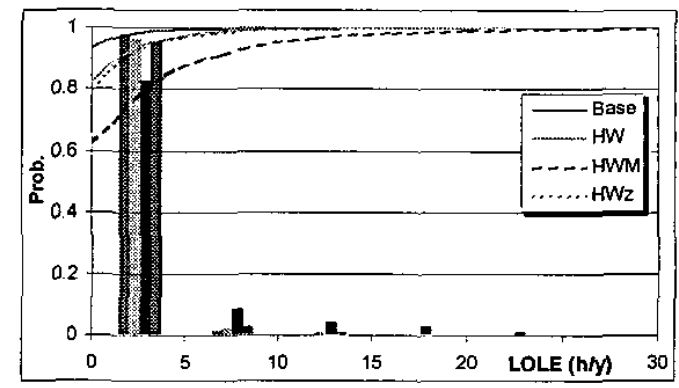

Fig. 9. Cumulative and Individual Prob. Functions for LOLE Indices - 2002.

The parameter $\beta$ was set to $5 \%$ in all tests for EENS index. Considering the "Base" case, 20764 years were simulated to ensure convergence and the system has visited 598645610 operating states. All simulations are carried out in a PC with $2.4 \mathrm{GHz}$. The CPU time was 19.3 minutes. Considering the HWM case, 2365 years were simulated to ensure convergence and the system visited 68691818 operating states. The CPU time in this case was 2.2 minutes.

\section{2) Analysis for the 2010 Configuration}

Tables III and IV and Figure 10 show results similar to the previous analysis but now considering the 2010 Configuration. In this case, the PGS has 1668 units with a total installed capacity of $17.83 \mathrm{GW}$, distributed as follows: $4.94 \mathrm{GW}$ (Hydro); $6.27 \mathrm{GW}$ (Thermal); $3.75 \mathrm{GW}$ (Wind); $0.45 \mathrm{GW}$ (Mini-hydro); and $2.42 \mathrm{GW}$ (Co-generation). The expected annual peak load forecasted for 2010 is $10.59 \mathrm{GW}$. The static reserve is now $40.6 \%$ of the total installed capacity,

TABLE III

CONVENTIONAL RFLIABLITY INDICES - 2010

\begin{tabular}{|c|c|c|c|c|c|}
\hline $\begin{array}{l}\text { Case } \\
\text { cro }\end{array}$ & $\begin{array}{l}\text { LOLE } \\
(\mathrm{h} / \mathrm{y})\end{array}$ & $\begin{array}{l}\text { EENS } \\
(\mathrm{MWh} / \mathrm{y})\end{array}$ & $\begin{array}{l}\text { LOLF } \\
(\text { oce } y)\end{array}$ & $\begin{array}{r}\text { LOLD } \\
\text { (h) }\end{array}$ & $\begin{array}{l}\mathbf{L O L C} \\
\times \mathbf{1 0} \mathbf{6} \mathbf{y}\end{array}$ \\
\hline Base & $\begin{array}{l}0.2564 \\
(3.46 \%)\end{array}$ & $\begin{array}{c}38.97 \\
(5.00 \%)\end{array}$ & $\begin{array}{l}0.2004 \\
(2.90 \%)\end{array}$ & $\begin{array}{c}1.279 \\
(3.90 \%)\end{array}$ & $\begin{array}{l}0.0585 \\
(5.00 \%)\end{array}$ \\
\hline HW & $\begin{array}{c}1.983 \\
(3.28 \%)\end{array}$ & $\begin{array}{c}301.7 \\
(5.00 \%)\end{array}$ & $\begin{array}{c}1.433 \\
(2.75 \%)\end{array}$ & $\begin{array}{c}1.383 \\
(3.61 \%)\end{array}$ & $\begin{array}{l}0.4526 \\
(5.00 \%)\end{array}$ \\
\hline HWM & $\begin{array}{c}11.01 \\
(3.60 \%)\end{array}$ & $\begin{array}{c}2029 \\
(5.00 \%)\end{array}$ & $\begin{array}{c}6.898 \\
(3.01 \%)\end{array}$ & $\begin{array}{c}1.597 \\
(4.30 \%)\end{array}$ & $\begin{array}{c}3.044 \\
(5.00 \%)\end{array}$ \\
\hline $\mathrm{HW}_{\mathrm{z}}$ & $\begin{array}{c}34.78 \\
(3.45 \%)\end{array}$ & $\begin{array}{c}6997 \\
(5.00 \%)\end{array}$ & $\begin{array}{c}18.77 \\
(2.81 \%)\end{array}$ & $\begin{array}{c}1.853 \\
(4.09 \%)\end{array}$ & $\begin{array}{c}10.50 \\
(5.00 \%)\end{array}$ \\
\hline
\end{tabular}

TABLE IV

WELL-BEING INDICES - 2010

\begin{tabular}{|c|c|c|c|c|c|c|}
\hline 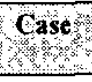 & $\begin{array}{c}\mathbf{E}_{\mathrm{H}} \\
(\mathrm{h} / \mathrm{y})^{\circ}\end{array}$ & $\begin{array}{l}\mathbf{E}_{\mathrm{N}} \\
(\mathrm{h} / \mathrm{y})\end{array}$ & $\begin{array}{c}\mathrm{F}_{\mathrm{H}} \\
(\mathrm{occ} / \mathbf{y})\end{array}$ & $\begin{array}{l}\mathrm{F}_{\mathrm{M}} \\
\text { (ocdy) }\end{array}$ & $\begin{array}{l}\mathbf{D}_{\boldsymbol{H}} \\
(\mathbf{h})_{3}\end{array}$ & 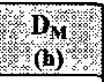 \\
\hline Base & $\begin{array}{c}8757 \\
(0.01 \%)\end{array}$ & $\begin{array}{r}2.370 \\
(5.00 \%) \\
\end{array}$ & $\begin{array}{r}1.796 \\
(4.57 \%) \\
\end{array}$ & $\begin{array}{r}1.930 \\
(4.68 \%) \\
\end{array}$ & $\begin{array}{r}4876 \\
(4.57 \%) \\
\end{array}$ & $\begin{array}{r}1.228 \\
(6.43 \%) \\
\end{array}$ \\
\hline HW & $\begin{array}{c}8742 \\
(0.01 \%)\end{array}$ & $\begin{array}{c}15.15 \\
(5.00 \%) \\
\end{array}$ & $\begin{array}{r}10.37 \\
(4.35 \%)\end{array}$ & $\begin{array}{c}11.45 \\
(4.57 \%)\end{array}$ & $\begin{array}{c}843.0 \\
(4.36 \%) \\
\end{array}$ & $\begin{array}{c}1.323 \\
(6.14 \%) \\
\end{array}$ \\
\hline HWM & $\begin{array}{r}8696 \\
(0.04 \%) \\
\end{array}$ & $\begin{array}{r}52.42 \\
(4.52 \%) \\
\end{array}$ & $\begin{array}{c}32.24 \\
(4.25 \%) \\
\end{array}$ & $\begin{array}{r}37.06 \\
(4.35 \%) \\
\end{array}$ & $\begin{array}{c}269.7 \\
(4.27 \%) \\
\end{array}$ & $\begin{array}{r}1.414 \\
(5.65 \%) \\
\end{array}$ \\
\hline $\mathrm{HW}_{2}$ & $\begin{array}{c}8602 \\
(0.05 \%)\end{array}$ & $\begin{array}{c}124.0 \\
(2.31 \%)\end{array}$ & $\begin{array}{c}70.16 \\
(2.09 \%)\end{array}$ & $\begin{array}{c}84.16 \\
(2.23 \%)\end{array}$ & $\begin{array}{c}122.6 \\
(2.10 \%)\end{array}$ & $\begin{array}{c}1.473 \\
(2.68 \%)\end{array}$ \\
\hline
\end{tabular}




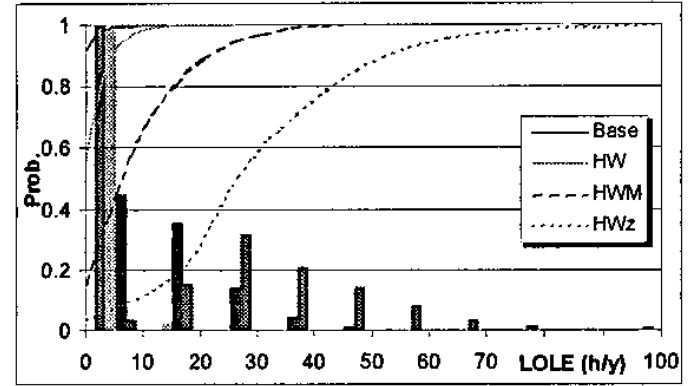

Fig. 10. Cumulative and Individual Prob. Functions for LOLE Indices -2010 .

Observe that the amount of wind power in the system has dramatically increased: $1.54 \%(2002)$ to $21.0 \%$ (2010). Also, the amount of total renewable has increased from $42.4 \%$ to $51.2 \%$. The worst condition occurs now for " $H W_{Z}$ ", resulting indices like: $\mathrm{LOLE}=34.78$ hours/year and the LOLC $=10.5$ million $\epsilon / y$ ear. Under this condition, the system will spend, on average, 124 hours in marginal states. The frequency of encountering marginal states is 84.16 occurrences per year. Figure 10 shows the cumulative and individual probability functions associated with the four previous conditions. As it can be seen, the probability of overcoming the previous LOLE limit is about 0.554 for "HWM", and 0.967 for "HW". If LOLE $=10$ hours/year is set as the acceptable limit for the PGS and considering extremely severe conditions, the 2010 Configuration would have to be reviewed.

\section{FINAL REMARKS}

The increased use of electricity produced from renewable energy sources constitutes an important part of the package of measures needed to comply with the Kyoto Protocol to the United Nations Framework Convention on Climate Change. The promotion of this type of electricity has a high priority in many countries, in particular, in the European Union. On the other hand, more renewable power sources cause to the system an increase in the number of random variables and operation complexities due to the fluctuating production levels of these sources. Therefore, the determination of the required amount of system capacity to guarantee an adequate supply becomes an extremely important aspect of generating capacity expansion analyses. For instance, considering one possible configuration of the Portuguese Generating System for 2010 and a suggested criterion (LOLE ${ }^{\text {acceptable }} \leq 10$ hours/year and the system has to survive the worst hydrological year simultaneously with nil wind condition), an additional amount of $250 \mathrm{MW}$ (through an equivalent tie-line) would be necessary to decrease the LOLE index from 34.7 to $10.0 \mathrm{~h} / \mathrm{yr}$. Discussions on innovative criteria, operation strategies and assessment tools will be the new insights of generating capacity expansion planning considering renewable power sources for the years to come.

\section{ACKNOWLEDGMENT}

The authors thank DGGE (Direcçăo Geral de Geologia e Energia) and REN (Rede Eléctrica Nacional), Portugal, for providing part of the data used in this work.

\section{REFERENCES}

[1] S. Rahman, "Green Power: What is it and where can we find it?", IEEE Power and Energy Magazine, Vol. 1, No. 1, pp. 30-37, Jan./Feb. 2003.

[2] European Union Directive 2001/77/EC, "On the promotion of electricity produced from renewable energy sources in the internal electricity market", Official Journal of the European Com. L283, Oct. 27, 2001.

[3] R. Billinton and R.N. Allan, "Reliability Evaluation of Power Systems", Plenum Press, New York, 1996.

[4] R. Billinton and E. Khan "A security based approach to composite power system reliability evaluation", IEEE Trans. on Power Systems, Vol. 7, No. 1, pp. 65-72, Feb. 1992.

[5] R. Billinton and G. Lian, "Composite power system health analysis using a security constrained adequacy evaluation proceduren", IEEE Trans. on Power System.s, Vol. 9, No. 2, pp. 936-941, May 1994.

[6] R. Billinton and M. Fotuhi-Finuzabad, "A basic framework for generating system operating health analysis", IEEE Trans. on Power Systems, Vol.9, No. 3, pp.1610-1617, Aug. 1994.

[7] R. Billinton and R. Karki, "Application of Monte Carlo simulation to generating system well-being analysis", IEEE Trans. on Power Systems, Vol. 14, No. 3, pp. 1172-1177, Aug. 1999.

[8] X. Wang, H. Dai and R.J. Thomas, "Reliability modeling of large wind farms and electric utility interface systems", IEEE Trans. on PAS, Vol. 103, No. 3, pp. 569-575, Mar. 1984.

[9] C. Singh and A. Lago-Gonzalez, "Reliability modeling of generation systems including unconventional energy sources", IEEE Trans. on PAS, Vol. 104, No. 5, pp. 1049-1056, May 1985.

[10] G. Desrochers and M. Blanchard, "A Monte Carlo simulation for the economical assessment of the contribution of wind energy to power systems", IEEE Trans. on Energy Conv., Vol. 1, No.4, pp. 50-56, 1986.

[11] R. Billinton and A.A. Chowdhury, "Incorporating of wind energy conversion systems in conventional generating capacity adequacy assessment", IEE Proc.-C, Vol. 139, No. 1, pp. 45-56, Jan. 1992.

[12] R. Billinton, H. Chen and R. Ghajar, "A sequential simulation technique for adequacy evaluation of generating systems including wind energy", IEEE Trans. on Energy Conv, Vol. 11, No. 4, pp. 728-734, 1996.

[13] F.C. Sayas and R.N. Allan, "Generation availability assessment of wind farms", IEE Proc.-Gener. Transm. Distrib., Vol. 143, No. 5, pp. 507518, Sept. 1996.

[14] R. Billinton, H. Chen, "Assessment of risk-based capacity benefit factors associated with wind energy conversion systems", IEEE Trans. on Power Systems, Vol. 13, No. 3, pp. 1191-1196, Aug. 1998.

[15] P. Wang and R. Billinton, "Reliability benefit analysis of adding WTG to a distribution system", IEEE Trans. on Energy Comv., Vol. 16, No. 2, pp. 134-139, June 2001.

[16] R. Billinton and R. Karki, "Capacity expansion of small isolated power systems using PV and wind energy", IEEE Trans. on Power Systems, Vol. 16, No. 4, pp. 892- 897, Nov. 2001.

[17] R. Karki and R. Billinton, "Reliability/Cost implications of PV and wind energy utilization in small isolated power systems", IEEE Trans. on Power Systems, Vol, 16, No. 4, pp. 368-373, Dec. 2001.

[18] R. Billinton, Bagen and Y, Cui, "Reliability evaluation of small standalone wind energy conversion systems using a time series simulation model", IEE Proc.-Gener. Transm. Distrib., Vol. 150, No. 1, pp. 96-100, Jan. 2003.

[19] A.M. Leite da Silva, A.C.G. Melo and S.H.F. Cunha, "Frequency and duration method for reliability evaluation of large-scale hydrothermal generating systems", IEE Proc.-C, Vol.138, No.1, pp.94-102, Jan. 1991.

[20] A.M. Leite da Silva, G. Perez A., J.W. Marangon Lima, J.C.O. Mello, "Loss of load costs in generating capacity reliability evaluation", Electric Power Systems Research, Vol. 41, pp. 109-116, May 1997.

[21] A.M. Leite da Silva, L.A.F. Manso, J.C.O. Mello, R. Billinton, "Pseudochronological simulation for composite reliability analysis with time varying loads", IEEE Trans. on Power Systems, Vol. 15, No. 1, pp. 7380 , Fev. 2000. 